\title{
Complications of injectable testosterone undecanoate in routine clinical practice
}

\section{T Middleton, L Turner, C Fennell, S Savkovic, V Jayadev, A J Conway and D J Handelsman}

Andrology Department, ANZAC Research Institute, Concord Hospital, University of Sydney, Sydney, New South Wales 2139, Australia
Correspondence should be addressed to D J Handelsman Email djh@anzac.edu.au

\begin{abstract}
Objective: Injectable testosterone undecanoate (TU) was marketed within the last decade, but its complications in routine clinical practice are not well defined.

Design and methods: Prospective observational study of consecutive TU injections in an Andrology Clinic to estimate the incidence of i) immediate cough/syncope due to pulmonary oil microembolisation (POME), ii) post-injection haematoma and iii) the prevalence of secondary polycythaemia.

Results: In 3022 injections given to 347 patients over 3.5 years, POME was observed after 56 injections (66\% mild, 19\% severe; $40 \%$ with onset before injection completed) in 43 patients. The incidence of 19 (95\% Cl 14-24) per 1000 injections did not differ between three experienced nurse injectors, but recurrences were more frequent than by chance. No post-injection haematoma was reported including after 269 injections to men taking antiplatelet, anticoagulant or both drugs (upper $95 \%$ confidence limit 1\%) with 56 not withholding drugs prior to TU administration (upper $95 \%$ confidence limit $5.4 \%$ ).

Mean haematocrit was $0.44 \pm 0.04$ (s.D.) with $25(7 \%)>0.50,14(4 \%)>0.52$ and $3(1 \%)>0.54$.

Conclusion: TU injections produce a low incidence of POME with injections by experienced nurses, but recurrence is more frequent than by chance. Post-injection haematoma was not observed even among men using anticoagulant and/or antiplatelet drugs, and polycythaemia was a minor problem rarely requiring treatment other than optimising inter-injection interval.
\end{abstract}

\section{Introduction}

Testosterone has been in clinical use for over 75 years (1) in a wide variety of products (2). Since the mid-1950s, injectable testosterone esters in oil vehicle (3) has been the most widely used testosterone formulation for its affordability and its depot properties which ease compliance by wide inter-injection spacing. Testosterone undecanoate (TU), available for decades in an oil-filled oral capsule marketed world-wide (other than the USA) $(4,5)$, was first developed as an injectable oil vehicle-based formulation in China in the 1980s (6) and subsequently reformulated for marketing in Europe in 2003 and subsequently worldwide over the last decade (7). Within that decade, TU has become one of the two most commonly prescribed testosterone products in Australia (8) and other countries (9).
(C) 2015 European Society of Endocrinology Printed in Great Britain
Testosterone replacement therapy for male hypogonadism due to pathological disorders of the reproductive system aims to restore the lifetime health outcomes of eugonadal men. While all testosterone products can provide effective testosterone replacement therapy, the choice of formulation is primarily determined by patient convenience and physician familiarity, aiming to assure long-term compliance with lifelong treatment (2). Similarly, while reviews of testosterone treatment focus mostly on efficacy rather than safety (10), generically, testosterone replacement therapy has a good safety record (11) while each product has specific side-effects mostly related to their mode of administration. For injectable testosterone esters in an oil vehicle, the most relevant are injection site pain (12) or haematoma, pulmonary oil

Published by Bioscientifica Ltd. 
microembolism (POME) $(13,14)$ and secondary polycythaemia (15). Most studies of testosterone's safety profile originate from clinical trials primarily designed to meet the requirements of regulatory authorities to enable a product to be marketed. It is common experience that post-marketing safety profile may differ from the clinical development program that achieves marketing approval with key differences arising for reasons including detection of rare and previously unrecognised events, confounding by between-centres differences in clinical practice, commercial motivations of sponsors and the artificial framework of clinical registration trials. We have therefore undertaken a prospective surveillance study of TU injections in the routine clinical practice in an experienced single academic centre outside a research setting with a focus on POME, haematoma and polycythaemia.

\section{Subjects and methods}

\section{Study design}

This study was a prospective survey of patients attending the Andrology Department of Concord Hospital to receive TU injections between July 2010 and March 2014 for androgen deficiency due to pathological disorders of the hypothalamo-pituitary-testicular axis. Blood was sampled for serum testosterone monitoring before testosterone injection. Testosterone injections were administered by the clinical staff of the Andrology Department according to the standard protocol by slowly administering deep i.m. injection into the upper outer quadrant of the buttock after aspiration to exclude venous injection. At the time of each injection, clinical staff recorded demographic details and observations for POME episodes between start of injection and leaving the clinic. POME was considered to be present when an unexpected, non-productive cough occurred during or immediately after (within minutes) TU injection. The coughing episode occurred with or without a sensation of flushing, faintness or anxiety and was not due to a chronic cough, acute asthma or an upper respiratory tract infection. Symptoms usually took a few (up to 10) minutes to resolve.

The departmental policy, on haematology advice, was to temporarily interrupt anticoagulants or antiplatelet medication before deep i.m. injections to prevent haematoma, subject to safety review by the doctor prescribing the anticoagulant or antiplatelet drug. In this study, men receiving antiplatelet and/or anticoagulant medications were asked whether they had stopped their medication and, if so, for how long, as well as whether they experienced a haematoma following their previous TU injection.

Patients were routinely monitored for polycythaemia by full blood counts at least once per year for men over the age of 50 years, as well as by cross-sectional campaign surveillance for the stable population of all men attending for regular testosterone replacement therapy.

\section{Subjects and injections}

The participants involved in this study were patients of the Andrology Department aged between 20 and 75 years, who were receiving testosterone replacement therapy for a variety of pathological disorders of the hypothalamic, pituitary or testis (but not andropause) or were femaleto-male transgender patients. Injections were administered by experienced nurses delivering deep i.m. injections of $1000 \mathrm{mg}$ of TU in $4 \mathrm{ml}$ of castor oil vehicle using a 21-gauge needle. Injections were administered deeply into the right and left gluteal muscle (on an alternating basis) slowly over a period of $2 \mathrm{~min}$. The patients were observed until they left the clinic, in most cases within a few minutes of receiving their injection. When patients experienced POME symptoms, they were observed until the symptoms resolved, usually within $10 \mathrm{~min}$ of the onset.

\section{Assays}

Haematocrit was measured by standard autoanalyser methods and serum testosterone by immunoassay.

\section{Statistical analysis}

Data were analysed by appropriate methods for continuous or categorical data using NCSS version 9 and StatXact version 9 software.

\section{Results}

During the 3.5 years of this survey, 3022 TU injections were administered to a total of 347 patients, whose androgen deficiency causes are given in Table 1.

\section{Cough/syncope episodes}

There were a total of 56 POME episodes observed in 43 patients, associated with TU giving an overall incidence of 19/1000 injections (95\% CI 14-24 per 1000 injections). One patient experienced a POME episode during his first i.m. TU injection and the remainder had received between 
Table 1 Causes of androgen deficiency.

\begin{tabular}{|c|c|}
\hline Cause of androgen deficiency & Number \\
\hline Primary hypogonadisma & 144 \\
\hline Secondary hypogonadism ${ }^{b}$ & 89 \\
\hline F2M transgender & 96 \\
\hline Other & 18 \\
\hline Total & 347 \\
\hline
\end{tabular}

${ }^{a}$ Klinefelter's syndrome, orchidectomy, cryptorchidism, testicular agenesis, trauma, infection, torsion or cytotoxic/irradiation damage.

${ }^{b}$ Kallmann's syndrome, IHH, pituitary or cerebral tumour, delayed puberty.

one and $30 \mathrm{TU}$ injections (median 17 previous asymptomatic injections, inter-quartile range (IQR) 17) before their observed POME episode in this study.

POME episodes were experienced by patients due to a wide variety of underlying clinical conditions comprising Klinefelter's syndrome (8, 19\%), idiopathic hypogonadotrophic hypogonadism including Kallmann's syndrome (7, 16\%), hypogonadism following castration $(4,9 \%)$, pituitary tumour/surgery $(4,9 \%)$, chemotherapy $(6,14 \%)$, other (testicular pathology, male contraception $5,12 \%$ ) or F2M transgender $(9,21 \%)$. These patients were aged between 22 and 74 years ( $26 \%$ aged $<35$ years, $42 \%$ aged $36-50$ years, $19 \%$ aged $51-65$ years and $12 \%$ aged 66 years and over) and had BMIs ranging from 15.2 to $38.3 \mathrm{~kg} / \mathrm{m}^{2}$ (median $25.7 \mathrm{~kg} / \mathrm{m}^{2}$; IQR $4.95 \mathrm{~kg} / \mathrm{m}^{2}$ ). There was no significant difference between men who had a POME episode in the time since last injection and in serum testosterone immediately before the index injection (Table 2).

Onset of symptoms was during injection for $40 \%$ and duration of coughing (documented for 51/56 episodes) ranged between 1 and $10 \mathrm{~min}$ (median duration $3 \mathrm{~min}$; IQR $3 \mathrm{~min}$ ). Severity of symptoms (documented 53/56) was recorded as very mild or mild (66\%), moderate (15\%) or severe (19\%). All episodes were managed conservatively within the clinic and supplementary oxygen was never required.

There was no significant difference between the rates of POME episodes observed between three experienced nurse injectors who administered 98\% (2973) of all injections (Table 3). The risk of recurrent episodes of cough/syncope (Table 4) was significantly greater than that expected by chance ( $P=0.034$, extended Fisher's test) deviating from a Poisson distribution (mean and variance $=0.12$ ).

\section{Haematoma}

Among the 3022 injections, 269 (prevalence 8.9\%) were administered to patients using prescribed antiplatelet (aspirin $n=225$; asasantin $n=3$; clopidogrel $n=15$; clopidogrel/aspirin $n=1$ ) or anticoagulant (warfarin $n=25$; enoxaparin $n=2$ ) therapy with two patients on both clopidogrel and warfarin. Although the clinic's routine practice based on haematological advice was for patients to temporarily interrupt antiplatelet/anticoagulant therapy before the TU injection, this was subject to the medical indication and judgement of the patient's doctor prescribing the antiplatelet/anticoagulant medication. Most patients did interrupt antiplatelet/anticoagulant treatment for a median of 7 days (aspirin median 7 , 1-28 days; clopidogrel median 4.5 days, 2-11 days; clexane median 4.5 days, 3-6 days; warfarin median 4 days, 2-94 days). For 56 injections, the antiplatelet/ anticoagulant medication was not interrupted. There were no patient reports of significant haematoma post-TU injection during this study period, giving an upper $95 \%$ confidence limit for significant haematoma of $0.1 \%$ for the whole population of men receiving TU injections, of $1.0 \%$ for men prescribed anticoagulant/antiplatelet medication and $5.4 \%$ for men who did not interrupt antiplatelet/anticoagulant medication.

\section{Polycythaemia}

Haematocrit measurement was available for 347 patients (with between one and 23 measurements available for each patient). Using the first measurement, the haematocrit was 0.44 (0.002 s.D.; quartiles $0.42,0.44,0.47$; range $0.31-0.56)$ with $25(7.2 \%)>0.50,14(4.0 \%)>0.52$ and $3(0.9 \%)>0.54$.

\section{Discussion}

Injectable TU has been marketed for over 10 years and is now one of the most commonly prescribed products for testosterone replacement therapy $(8,9)$. While the safety profile under clinical trial conditions is well established

Table 2 Inter-injection interval and trough serum testosterone.

\begin{tabular}{|c|c|c|}
\hline & Cough & No cough \\
\hline Number of injections & 55 & 2750 \\
\hline \multicolumn{3}{|l|}{$\begin{array}{l}\text { Time since previous injection } \\
\text { (days) }\end{array}$} \\
\hline $\begin{array}{l}\text { Mean } \pm \text { s.E.M. } \\
\text { Median (quartiles) }\end{array}$ & $\begin{array}{c}87 \pm 7 \\
84(70,86)\end{array}$ & $\begin{array}{c}89 \pm 1 \\
84(70,90)\end{array}$ \\
\hline \multicolumn{3}{|l|}{ Serum testosterone $(\mathrm{nmol} / \mathrm{l})$} \\
\hline Mean \pm s.E.M. & $16.2 \pm 1.1$ & $15.9 \pm 0.1$ \\
\hline Median (quartiles) & $13.7(11.5,21.0)$ & $14.8(11.3,19.4)$ \\
\hline
\end{tabular}

No difference between injections with or without cough (all $P$ values $>0.70$ ). 
Table 3 Number and rate per injection of cough/syncope episodes according to experienced nurse injectors.

\begin{tabular}{|c|c|c|c|}
\hline Nurse & $\begin{array}{l}\text { Number of } \\
\text { injections }\end{array}$ & $\begin{array}{l}\text { Cough/syncope } \\
\text { episodes }\end{array}$ & $\begin{array}{l}\text { Rate of cough/syncope } \\
\text { (per } 100 \text { injections) }\end{array}$ \\
\hline 1 & 1286 & 27 & 2.1 \\
\hline 2 & 714 & 10 & 1.4 \\
\hline 3 & 973 & 20 & 2.1 \\
\hline
\end{tabular}

$(16,17,18,19,20,21)$, its complications in routine clinical practice outside clinical trials have been less clearly established.

This study provides the most detailed characterisation of the clinical features of POME since its original description in men having deep gluteal i.m. injections of $0.8 \mathrm{ml}$ testosterone enanthate in castor oil vehicle (13). This was subsequently confirmed in a Chinese study involving regular gluteal i.m. injections of $500 \mathrm{mg}$ TU in $4 \mathrm{ml}$ mellaleuca (mistranslated as 'tea seed') oil (14). In this study, POME has a rapid onset, usually during injection or shortly thereafter, lasting $<10$ min (median $3 \mathrm{~min}$ ) and mostly mild in severity with no lasting sequelae. Its occurrence seems unrelated to age, underlying cause of hypogonadism or experienced nurses administering injections. The study design precluded evaluating the impact on POME incidence of less experienced nurses or doctors. It may also underestimate the occurrence of POME episodes that occurred after the patients left the clinic; however, based on our experience we believe this is rare if it ever occurs. The incidence in this study of $19 / 1000$ injections is close to the rate originally described of 15 (95\% CL 6-29) per 1000 injections (13) where both used castor oil vehicle, although with more different volumes ( 4 vs $0.8 \mathrm{ml}$ ) per injection. These estimates are however very different from the much lower incidence of POME reported to the FDA during the clinical development (1.5 cases/10 000 injections) and during post-marketing surveillance (0.7 cases/10 000 injections) in the US registration clinical trials of injectable TU (750 mg in $3 \mathrm{ml}$ castor oil) (22). This major apparent discrepancy may be due to the manner of recording POME in the US clinical trials, which were marked by the incidence of POME being a significant hurdle to FDA registration. In addition to reducing the injection volume from 4 to $3 \mathrm{ml}$, the sponsor of the clinical trials employed two independent adjudicators, both former FDA employees without clinical experience of testosterone injections, who created an ad hoc case definition of POME after the conclusion of the trials.
The essential major criterion was paroxysmal cough with undue emphasis on the paroxysmal pattern. Using this case definition and written reports from centres, they discounted 97\% (107 of 110 reports in 102 men) of putative POME reports with 23 regarded as 'intermediate' and 84 as not POME. No specific definition of 'intermediate' cases was provided, but if the 'intermediate' cases were included the rate of POME is comparable with our findings (13 vs 19/1000 injections). Systematic underreporting of adverse cardiovascular effects of testosterone has been reported in commercially sponsored clinical trials (23).

The mechanism of POME appears to involve inadvertent entry of injected oil vehicle into the venous circulation with subsequent transfer to the pulmonary microvasculature. The basis for this interpretation arises from experimental animal studies showing pulmonary embolism in dogs and rabbits following i.m. injection of vegetable oils (24). There is also corroborative clinical evidence of lymphogenic absorption in humans after oil vehicle depot injections (25) as well as following accidental introduction of oil-based radiocontrast into the bloodstream during myelography, which produced cough and radiographic visualisation of contrast in the lungs $(26,27,28)$. This non-thrombotic mechanism of POME should not be confused with the numerous prothrombotic genetic thrombophilias, such as Factor V Leiden (29). These features suggest that POME would be a random event, an interpretation supported by the lack of influence of age, underlying disease or between-injector differences among experienced nurses; however, the nonrandom risk of recurrence suggests that additional factors such as anatomical differences between individuals or of expectation by non-blinded reporters may be involved. Interestingly, confirming the higher than expected rate of POME recurrence, in the reported US clinical trials, eight of 102 men (8\%) experienced a second episode of POME and one of ten men (10\%) with 'intermediate' POME

Table 4 Frequency of cough/syncope episodes and recurrences.

\begin{tabular}{l}
$\begin{array}{l}\text { Number of cough/syncope } \\
\text { episodes per patient }\end{array}$ \\
\hline 0 \\
1 \\
2 \\
3 \\
\hline
\end{tabular}

\begin{tabular}{ccc}
$\begin{array}{c}\text { Number of } \\
\text { patients }\end{array}$ & & $\begin{array}{c}\text { Expected } \\
\text { number }\end{array}$ \\
\cline { 1 - 1 } 305 & & 306 \\
30 & 37 \\
10 & & 2 \\
2 & 0 \\
\hline
\end{tabular}

${ }^{\mathrm{a}}$ According to Poisson distribution with mean and variance $=0.12$ 
experienced a recurrence, both of which greatly exceeded the study's reported overall incidence of POME (22).

One potential adverse effect of deep i.m. injections of a large volume of oil vehicle is the risk of injectioninduced haematoma. This risk is greatest among men with a bleeding disorders or using anticoagulant or antiplatelet medication indicated by incidental co-morbidities, and has led to recommendations that i.m. injections should not be given to men taking anticoagulants $(30,31)$. Nevertheless, previous small studies have shown that i.m. injection in an aqueous vehicle can be administered safely to patients receiving anticoagulant medications without increased risk of local bleeding $(32,33,34,35,36)$; however, the use of larger volume of oil vehicle may change such risks. This study, based on self-report, did not record any instance of post-injection haematoma, allowing us to establish plausible upper 95\% confidence limits on the risk of post-injection haematoma as $0.1 \%$ for all men having TU injections, $1 \%$ for men using anticoagulant or antiplatelet medication but who interrupt that medication temporarily for the TU injection and 5.4\% for men continuing to use such medication at the time of $\mathrm{TU}$ injection. These findings are reassuring that such post-injection haematoma is a relatively low risk for men having TU injection, including those taking antiplatelet or anticoagulant medication. The present findings are consistent with the pooled European and US clinical registration studies for 750 and $1000 \mathrm{mg}$ TU injections in 3 and $4 \mathrm{ml}$ castor oil vehicle, respectively, where there were only two reports of injection site haematoma/ haemorrhage among 725 patients (22); whether these men were using anticoagulant or antiplatelet medications is not reported.

Testosterone has prominent dose-dependent stimulatory effect on erythropoiesis, involving stimulation of erythropoietin, suppression of hepcidin and increased iron incorporation into erythrocytes $(37,38,39,40)$. Consequently, testosterone replacement therapy can result in polycythaemia $(11,41)$, which is more prominent among older men (42) and those having injectable or implantable rather than oral testosterone (15). The incidence of treatment emergent polycythaemia resulting in discontinuation of injectable TU in clinical studies carried out in United States and European Union was 1.8\% (22); however, as an expected side-effect of testosterone treatment, less severe polycythaemia may be more frequent without requiring discontinuation of treatment. The present study confirms that mild polycythaemia is not unusual during TU injections, but is rarely severe and usually manageable by wider inter-injection spacing with or without temporary suspension of TU treatment. No men in this study required venesection, anticoagulation or discontinuation of testosterone treatment.

In conclusion, TU injection is a generally safe and well-tolerated treatment. POME presenting as cough/ syncope symptoms during TU injection is uncommon, occurring with about $2 \%$ of TU injections. It is rapid in onset, usually evident during or immediately after TU injection, and lasting for up to $10 \mathrm{~min}$ but resolving fully without serious sequelae. While it appears to be a random event, unrelated to age, underlying disease or which experienced nurse injector, based on inadvertent access of the oil vehicle to the venous system, its risk of recurrence exceeds chance. Haematoma after deep i.m. $\mathrm{TU}$ injection is rare even among men using antiplatelet or anticoagulant medications at the time of injection and while mild polycythaemia is relatively common, it is rarely severe or requiring specific treatment other than optimising inter-injection interval.

\section{Declaration of interest}

The authors declare that there is no conflict of interest that could be perceived as prejudicing the impartiality of the research reported.

In 2015 the Andrology department expects to receive support for an investigator-initiated study of testosterone pharmacology (Lawley) and testosterone and placebo drug supply for an investigator-initiated study of testosterone treatment (Besins).

\section{Funding}

This research did not receive any specific grant from any funding agency in the public, commercial or not-for-profit sector.

\section{References}

1 Hamilton JB. Treatment of sexual underdevelopment with synthetic male hormone substance. Endocrinology 193721 649-654. (doi:10.1210/endo-21-5-649)

2 Handelsman DJ. Androgen physiology, pharmacology and abuse. In Endocrinology, edn 6, pp 2469-2498. Eds LJ DeGroot \& JL Jameson, Philadelphia: Elsevier Saunders, 2010.

3 Junkman K. Long-acting steroids in reproduction. Recent Progress in Hormone Research 195713 380-419.

4 Nieschlag E, Mauss J, Coert A \& Kicovic P. Plasma androgen levels in men after oral administration of testosterone or testosterone undecanoate. Acta Endocrinologica 197579 366-374.

5 Kohn FM \& Schill WB. A new oral testosterone undecanoate formulation. World Journal of Urology 200321 311-315. (doi:10.1007/ s00345-003-0372-x)

6 Zhang GY, Gu YQ, Wang XH, Cui YG \& Bremner WJ. A pharmacokinetic study of injectable testosterone undecanoate in hypogonadal men. Journal of Andrology 199819 761-768.

7 Nieschlag E. Testosterone treatment comes of age: new options for hypogonadal men. Clinical Endocrinology 200665 275-281. (doi:10.1111/j.1365-2265.2006.02618.x) 
8 Handelsman DJ. Pharmacoepidemiology of testosterone prescribing in Australia, 1992-2010. Medical Journal of Australia 2012196 642-645. (doi:10.5694/mja11.11277)

9 Handelsman DJ. Global trends in testosterone prescribing 2000-11: expanding the spectrum of prescription drug misuse. Medical Journal of Australia 2013199 548-551. (doi:10.5694/mja13.10111)

10 Corona G, Maseroli E \& Maggi M. Injectable testosterone undecanoate for the treatment of hypogonadism. Expert Opinion on Pharmacotherapy 201415 1903-1926. (doi:10.1517/14656566.2014. 944896)

11 Fernandez-Balsells MM, Murad MH, Lane M, Lampropulos JF, Albuquerque F, Mullan RJ, Agrwal N, Elamin MB, Gallegos-Orozco JF, Wang AT et al. Clinical review 1: Adverse effects of testosterone therapy in adult men: a systematic review and meta-analysis. Journal of Clinical Endocrinology and Metabolism 201095 2560-2575. (doi:10.1210/ jc.2009-2575)

12 Sartorius G, Fennell C, Spasevska S, Turner L, Conway AJ \& Handelsman DJ. Factors influencing time course of pain after depot oil intramuscular injection of testosterone undecanoate. Asian Journal of Andrology 201012 227-233. (doi:10.1038/aja.2010.1)

13 Mackey MA, Conway AJ \& Handelsman DJ. Tolerability of intramuscular injections of testosterone ester in an oil vehicle. Human Reproduction 199510 862-865.

14 Gu Y, Liang X, Wu W, Liu M, Song S, Cheng L, Bo L, Xiong C, Wang X, Liu X et al. Multicenter contraceptive efficacy trial of injectable testosterone undecanoate in Chinese men. Journal of Clinical Endocrinology and Metabolism 200994 1910-1915. (doi:10.1210/jc. 2008-1846)

15 Jockenhovel F, Vogel E, Reinhardt W \& Reinwein D. Effects of various modes of androgen substitution therapy on erythropoiesis. European Journal of Medical Research 19972 293-298.

16 Minnemann T, Schubert M, Freude S, Hubler D, Gouni-Berthold I, Schumann C, Christoph A, Oettel M, Ernst M, Mellinger U et al. Comparison of a new long-acting testosterone undecanoate formulation vs testosterone enanthate for intramuscular androgen therapy in male hypogonadism. Journal of Endocrinological Investigation 200831 718-723. (doi:10.1007/BF03346421)

17 Morgentaler A, Dobs AS, Kaufman JM, Miner MM, Shabsigh R, Swerdloff RS \& Wang C. Long acting testosterone undecanoate therapy in men with hypogonadism: results of a pharmacokinetic clinical study. Journal of Urology 2008180 2307-2313. (doi:10.1016/ j.juro.2008.08.126)

18 Wang C, Harnett M, Dobs AS \& Swerdloff RS. Pharmacokinetics and safety of long-acting testosterone undecanoate injections in hypogonadal men: an 84-week phase III clinical trial. Journal of Andrology 201031 457-465. (doi:10.2164/jandrol.109.009597)

19 Aversa A, Bruzziches R, Francomano D, Spera G \& Lenzi A. Efficacy and safety of two different testosterone undecanoate formulations in hypogonadal men with metabolic syndrome. Journal of Endocrinological Investigation 201033 776-783. (doi:10.1007/ BF03350341)

20 Schubert M, Minnemann T, Hubler D, Rouskova D, Christoph A, Oettel M, Ernst M, Mellinger U, Krone W \& Jockenhovel F. Intramuscular testosterone undecanoate: pharmacokinetic aspects of a novel testosterone formulation during long-term treatment of men with hypogonadism. Journal of Clinical Endocrinology and Metabolism 200489 5429-5434. (doi:10.1210/jc.2004-0897)

21 Nieschlag E, Buchter D, Von Eckardstein S, Abshagen K, Simoni M \& Behre HM. Repeated intramuscular injections of testosterone undecanoate for substitution therapy in hypogonadal men. Clinical Endocrinology 199951 757-763. (doi:10.1046/j.1365-2265. 1999.00881.x)

22 Endo Pharmaceuticals Solutions, Inc 2013 AVEED $^{\mathrm{TM}}$ (Testosterone Undecanoate) for Testosterone Replacement for Treatment of Hypogonadism. Available at http://www.fda.gov/downloads/ advisorycommittees/committeesmeetingmaterials/drugs/ reproductivehealthdrugsadvisorycommittee/ucm348092. pdf, Accessed 2 Oct 2014.

23 Xu L, Freeman G, Cowling BJ \& Schooling CM. Testosterone therapy and cardiovascular events among men: a systematic review and meta-analysis of placebo-controlled randomized trials. BMC Medicine 201311 108. (doi:10.1186/1741-7015-11-108)

24 Svendsen $\mathrm{O} \&$ Aaes-Jorgensen T. Studies on the fate of vegetable oil after intramuscular injection into experimental animals. Acta Pharmacologica et Toxicologica 197945 352-378. (doi:10.1111/j.16000773.1979.tb02404.x)

25 Svendsen O, Dencker SJ, Fog R, Gravem AO \& Kristansen P. Microscopic evidence of lymphogenic absorption of oil in humans receiving neuroleptic oily depot preparations intramuscularly. Acta Pharmacologica et Toxicologica 198047 157. (doi:10.1111/j.1600-0773.1980. tb01856.x)

26 Keats TE. Pantopaque pulmonary embolism. Radiology 195667 748-750. (doi:10.1148/67.5.748)

27 Bron KN, Baum S \& Abrams HL. Oil embolism in lymphography. Incidence, manifestations, and mechanisms. Radiology 196380 194-202. (doi:10.1148/80.2.194)

28 Gough JH \& Thomas ML. Pulmonary complications following lymphography. British Journal of Radiology 196437 416-421. (doi:10.1259/0007-1285-37-438-416)

29 Martinelli I, De Stefano V \& Mannucci PM. Inherited risk factors for venous thromboembolism. Nature Reviews. Cardiology 201411 140-156. (doi:10.1038/nrcardio.2013.211)

30 Aronson JK. Routes of drug administration: uses and adverse effects: part 1: intramuscuar and subcutaneous injection. Adverse Drug Reaction Bulletin 2008253 971-974.

31 Dyk T. Intramuscular injection and coagulation defects. BMJ 19724 795. (doi:10.1136/bmj.4.5843.795)

32 Raj G, Kumar R \& McKinney WP. Safety of intramuscular influenza immunization among patients receiving long-term warfarin anticoagulation therapy. Archives of Internal Medicine 1995155 1529-1531. (doi:10.1001/archinte.1995.00430140104011)

33 Casajuana J, Iglesias B, Fabregas M, Fina F, Valles JA, Aragones R, Benitez M \& Zabaleta E. Safety of intramuscular influenza vaccine in patients receiving oral anticoagulation therapy: a single blinded multi-centre randomized controlled clinical trial. BMC Blood Disorders 20088 1. (doi:10.1186/1471-2326-8-1)

34 Evans DI \& Shaw A. Safety of intramuscular injection of hepatitis B vaccine in haemophiliacs. BMJ 1990300 1694-1695. (doi:10.1136/ bmj.300.6741.1694-a)

35 Delafuente JC, Davis JA, Meuleman JR \& Jones RA. Influenza vaccination and warfarin anticoagulation: a comparison of subcutaneous and intramuscular routes of administration in elderly men. Pharmacotherapy 199818 631-636.

36 Ballester Torrens Mdel M, Aballi Acosta M, Maudos Perez MT, Iglesias Perez B, Casajuana Brunet J, Losada Doval G \& Piqueras Garre Mdel M. Intramuscular route for the administration of the anti-flu vaccine in patients receiving oral anticoagulation therapy. Medicina Cĺnica 2005 124 291-294. (doi:10.1157/13072321)

37 Bachman E, Travison TG, Basaria S, Davda MN, Guo W, Li M, Connor Westfall J, Bae H, Gordeuk V \& Bhasin S. Testosterone induces erythrocytosis via increased erythropoietin and suppressed hepcidin evidence for a new erythropoietin/hemoglobin set point. Journals of Gerontology. Series A, Biological Sciences and Medical Sciences 201469 725-735. (doi:10.1093/gerona/glt154)

38 Guo W, Bachman E, Li M, Roy CN, Blusztajn J, Wong S, Chan SY, Serra C, Jasuja R, Travison TG et al. Testosterone administration inhibits hepcidin transcription and is associated with increased iron incorporation into red blood cells. Aging Cell 201312 280-291. (doi:10.1111/acel.12052)

39 Bachman E, Feng R, Travison T, Li M, Olbina G, Ostland V, Ulloor J, Zhang A, Basaria S, Ganz T et al. Testosterone suppresses hepcidin in men: a potential mechanism for testosterone-induced erythrocytosis. 
Journal of Clinical Endocrinology and Metabolism 201095 4743-4747. (doi:10.1210/jc.2010-0864)

40 Ip FF, di Pierro I, Brown R, Cunningham I, Handelsman DJ \& Liu PY. Trough serum testosterone predicts the development of polycythemia in hypogonadal men treated for up to 21 years with subcutaneous testosterone pellets. European Journal of Endocrinology 2010162 385-390. (doi:10.1530/EJE-09-0717)

41 Calof OM, Singh AB, Lee ML, Kenny AM, Urban RJ, Tenover JL \& Bhasin S. Adverse events associated with testosterone replacement in middle-aged and older men: a meta-analysis of randomized, placebo-controlled trials. Journals of Gerontology. Series A, Biological Sciences and Medical Sciences 200560 1451-1457. (doi:10.1093/gerona/ 60.11.1451)

42 Coviello AD, Kaplan B, Lakshman KM, Chen T, Singh AB \& Bhasin S. Effects of graded doses of testosterone on erythropoiesis in healthy young and older men. Journal of Clinical Endocrinology and Metabolism 200893 914-919. (doi:10.1210/jc.20071692)

Received 17 October 2014

Revised version received 23 December 2014

Accepted 30 January 2015 